\title{
DENTAL ARCH EXPANSION AFTER ALVEOLAR CLEFT REPAIR USING AUTOGENOUS BONE MARROW DERIVED MESENCHYMAL STEM CELLS VERSUS AUTOGENOUS CHIN BONE GRAFT
}

\author{
Mahmoud E. Khalifa* and Nahla E. Goma***
}

\begin{abstract}
Alveolar cleft repair is well established, with bone grafting in mixed dentition phase. Mesenchymal derived stem cells were applied to different kinds of bone substitute and compared in different animal models..This study aimed to evaluate the bone quality and quantity at the alveolar cleft sites that were repaired with autogenous mesenchymal stem cell and its effect on orthodontic dental arch expansion and compare these results with cases treated with autogenous chin bone graft.
\end{abstract}

Patients and methods: 16 patients (14 left and 2 right, 9 males and 7 females)with unilateral alveolar cleft were included in this study. The age range was 7-12 yearswithmean age was 9.5 years. The alveolar cleft was repaired surgically and the patients were divided into 2 groups ( 8 patients in each one)according to surgical technique of repair. Group I ( 5 males and 3 females) : surgical repair was done by using autogenous bone marrow derived mesenchymal stem cells. Group II ( 4 males and 4 females): surgical repair was done by using autogenous chin bone grafting. The patients were undergo to orthodontic dental arch expansion and followed up to 18 months clinically and radiographically to evaluate and compare the effect of grafting types on arch expansion.

Results: The results of this study revealed that the patients in group I who treated by stem cell technology have a clinical results superior than the patients in group II who treated with chin bone grafting. Radiographic results revealed that in group I the bone quality and quantity were superior than that in group II.

Conclusion: The autogenous bone marrow derived mesenchymal stem cells is a good technique in repair of alveolar cleft as it promote the bone healing capacity with high quantity and quality as well as enhance orthodontic arch expansion.

KEY WORDS: Alveolar cleft, mesenchymal stem cell, chin bone graft, orthodontic arch expansion.

\footnotetext{
${ }^{a}$ Assistant prof Oral and Maxillofacial surgery .Faculty of dentistry, Tanta University, Egypt

${ }^{b}$ Lecturer of Orthodontics Faculty of dentistry, Tanta University, Egypt
} 


\section{INTRODUCTION}

Repair of bony defects continues to remain a challenging part of many reconstructive procedures. Currently, the gold standard for grafting of bone defects is the use of autogenous bone ${ }^{[1]}$.

In conventional methods, autogenous bone grafting has become an essential step in treating patients with alveolar cleft, and allows the placement of dental implants for missing teeth in the final stages of treatment ${ }^{[2]}$.

A successful graft supplies bone for erupting teeth and periodontal support for teeth adjacent to the cleft. It also gives more support and elevation of the alarbase on the affected side, thereby improving nasal symmetry. Alveolar grafting also stabilizes the separated maxillary segments and provides proper alveolar contour and prevents maxillary arch collapse. The graft also connects the disconnected segments to the mobile premaxilla in cases of bilateral cleft ${ }^{[3,4]}$.

Fresh autogenous bone is the ideal graft because it supplies living immunocompatible bone cells essential for osteogenesis. Therefore, its transplantation is still the gold standard when harvested from sites such as iliac crest, mandible, tibia, rib, or calvarium ${ }^{[5,6]}$. However, autogenous bone grafting is often related to disadvantages such as limited availability and donor site morbidity ${ }^{[7]}$.

Another material, such as allergenic bone, can present an advantage in terms of reduced morbidity, and can be used during alveolar bone grafting, but it is not as beneficial as autogenous bone ${ }^{[8,9]}$. Favorable results using bone morphogenetic protein 2 (BMP-2) for reconstruction of the alveolar cleft have been reported in the literature, but more studies are necessary to assess the bone quality in the long term ${ }^{[10]}$. Loss of the bone graft, reopening of the oronasal fistula, or both can happen, although secondary bone graft failures are considered uncommon ${ }^{[11]}$.

Tissue engineering technique involving mesenchymal stromal/stem cells (MSC) of various sources is an alternative to the traditional iliac crest bone graft. MSC with osteogenic potential placed within a biocompatible platform to enhance bone regeneration or recovery in patients with CLP ${ }^{[12]}$.

Mesenchymal stem cells (MSCs), which can be isolated from the marrow cavity as well as from the trabecular compartment, have been shown tohave the ability to form new bone when transplanted ${ }^{[2]}$.

Bone substitution materials can be combined with vital cells such as MSCs to increase boneformation ${ }^{[13-16]}$.Both synthetic and allograft materials allow adhesion and growth of osteoblastic cells, orosteogenic differentiation of precursor cells in vitro ${ }^{[17-19]}$.

On the base of complications of traditional bone graft, the aim of this study was to evaluate the bone quality and quantity at the alveolar cleft sites that were repaired with autogenous mesenchymal stem cell and its effect on orthodontic arch expansion and compare these results with cases treated with autogenous chin bone graft.

\section{PATIENTS AND METHODS}

Sixteen patients with unilateral alveolar clefts(14left and 2rights cases)were included in this study. The age of patients were ranged between 7 - 12years with mean age was 9.5 years. They were all treated by secondary grafting procedures of their alveolar clefts. The patients were selected, examined both clinically and radiographically and surgically managed at the Oral and Maxillofacial surgery Department, Faculty of Dentistry, Tanta University. Maxillary expansion was done at the Orthodontic Department, Faculty of Dentistry, Tanta University

Careful extra oral and intraoral clinical examinations were performed to determine the main chief complaint and also to evaluate the stability of maxillary segments, presence of old scar, asymmetry of the alar base, presence of oronasal fistula and the presence of erupting teeth in the cleft. 
Panoramic radiographs were done for each patient and examined as regard: the morphology of the cleft area, the size of the cleft side, the presence or absence of permanent lateral incisor and canine, the development of root length, presence and position of supernumerary teeth and stage of eruption of permanent canine and lateral incisor. In addition, Quantitative axial computed tomography (CT) scans were done for each patient to assess and measure local bone mineral density.

Patients were divided into 2 groups according to surgical techniques used for alveolar cleft repair.

Eight patients (group I) were treated by tissue engineering technology using autogenous mesenchymal stem cell and Nano bone as scaffold .
Another eight patients (group II) were treated with autogenous chin bone grafting.

This study was performed after receiving the approval of the ethical committee of Faculty of Dentistry, Tanta University. Written consents were signed by the parents or corresponding relatives to participate in this study.

\section{The surgical procedures in group I}

\section{A. Stem cell preparation}

In the cell culture lab, human MSCs were isolated and loaded into scaffold according to Soleymani et $\mathrm{a}^{[20]}$ who was used the stem cells in human sinus augmentation.

The following steps were done (Fig1\&2)
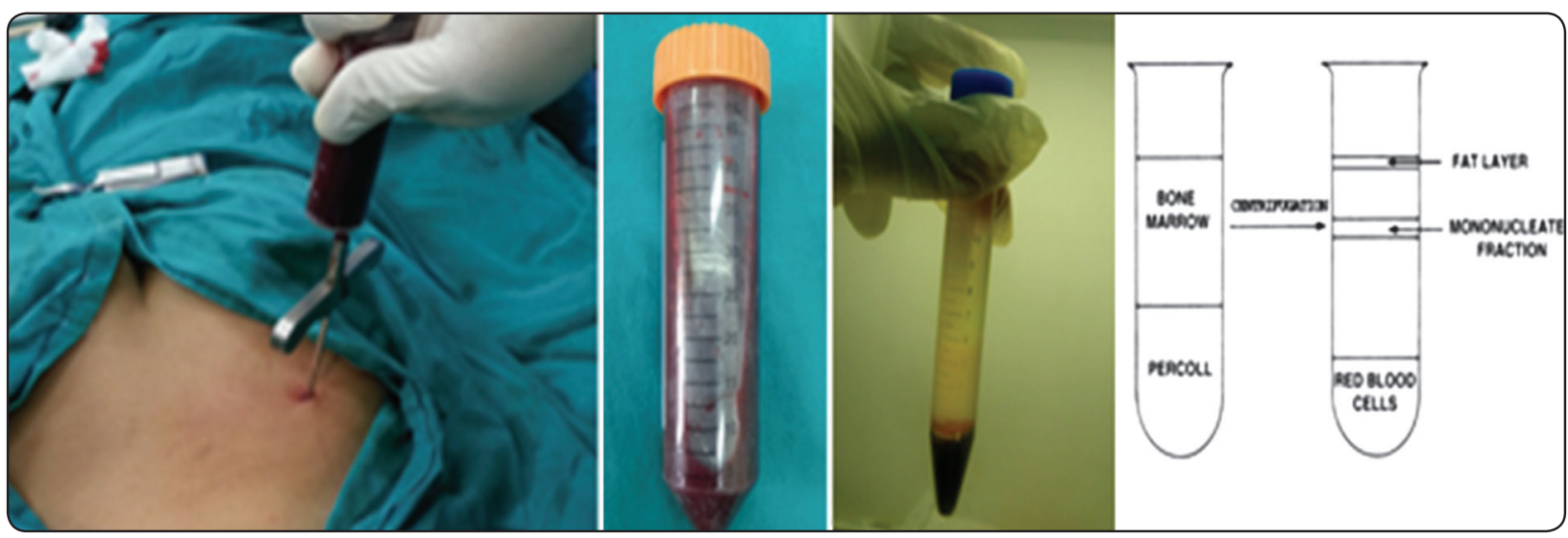

Fig (1)Showing bone marrow aspiration from posterior iliac crest, Isolation and cultivation of mesenchymal stem cells

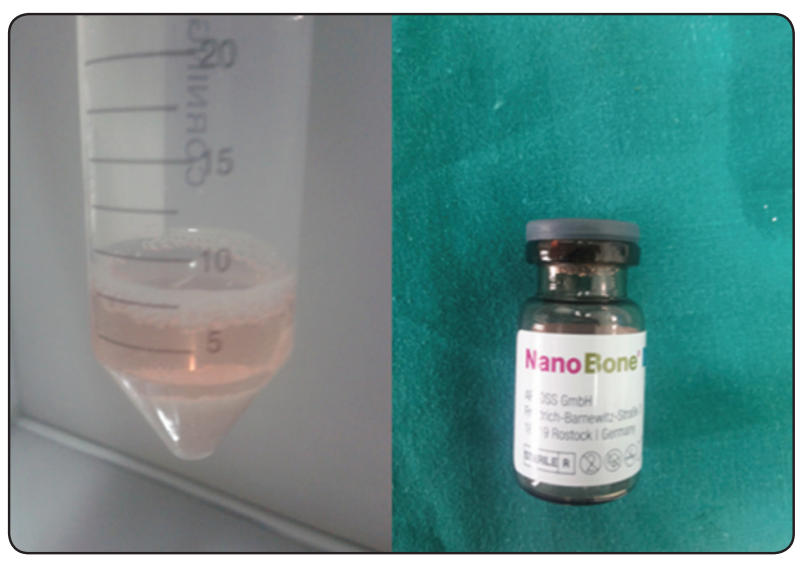

Fig (2) Implant preparation: Nano bone after loading by MSC
Isolation and cultivation of mesenchymal stem cells ${ }^{(20)}$

Two weeks before surgery a bone marrow aspirate (10-15 ml) was obtained from the posterior iliac crest. The aspirate was diluted at $1: 3$ in Dulbecco's modified Eagle's medium (DMEM) (Gibco, Paisley, UK). On day 1, non-adherent cells were discardedand adherent cells were washed with phosphate-buffered saline(PBS) (Gibco) and then cultured in DMEM medium with antibioticsand $20 \%$ autologous serum. 


\section{Preparation of human serum}

FCS was replaced by human serum because of concerns of the ethical committee. From each patient $20 \mathrm{ml}$ of whole blood was drained into blood bags (Baxter, Deerfield, IL), quickly transferred to10 $\mathrm{ml}$ vacationer tubes without anticoagulants (BD, Plymouth, UK), and allowed to clot for $4 \mathrm{~h}$ at $4^{\circ} \mathrm{C}-8^{\circ} \mathrm{C}$. Subsequently, the blood was centrifuged at $1800 \mathrm{~g}$ at $4{ }^{\circ} \mathrm{C}$ for $15 \mathrm{~min}$. Serum was collected and filtered through a $0.2 \mathrm{~m}$ membrane (Sarstedt, Nümbrecht, Germany). Aliquots of the sterile serum were stored at $20^{\circ} \mathrm{C}$. The lab process and cultivation of the cells for each patient was performed

\section{B. Implant preparation}

NanoBone ${ }^{\circledR}$ granulate (ARTOSS GmbH Friedrich-Barnewitz-Straße3 18119 Rostock,Germany) was used in this study. It is the first NanoBone ${ }^{\circledR}$ technology product and was launched in $2005^{20}$. When mixed with blood NanoBone ${ }^{\circledR}$ takes on a paste-like consistency and can be applied easily and effectively with an augmentation spoon or spatula. It is vary from fine $(0.6 \times 2 \mathrm{~mm})$ and rough $(1$ x $2 \mathrm{~mm}$ ). One day before transplantation, implants were loaded by the cells obtained from the third subculture of the patient bone marrow derived stem cells. The cylinders were first washed with PBS and then loaded with MSCs by placing $5^{*} 10^{5}$ cells in $0.2 \mathrm{~mL}$ DMEM medium on top of it.

\section{Surgical technique}

Surgery was carried out under general anesthesia. Following a Crestal line incision at the level of the gingival sulcus. The mucoperiosteal flaps were then elevated to the levels of the anterior nasal spine anteriorly, the lateral piriform rim superiorly, and to the alveolar ridges inferiorly.

Palatal flaps were developed by starting reflection of the palatal flaps from a sulcular incision that is placed on the palatal side of the dentition toward the palatal defect. The palatal flaps then separated from the nasal tissue along the cleft margin by sharp dissection. Once the buccal and palatal flaps have been developed, access is readily obtained to the nasal mucosa, which is then reflected and sutured, burying the knots to obtain a watertight nasal closure. Once the nasal mucosa is closed, the palatal defect is closed by first closing the palatal flaps, converting the cleft palate into a single flap. The scaffold NanoBone ${ }^{\circledR}$ loaded with cells was transferred to the defect by micro-forceps then the wound was closed in a watertight manner.

\section{The surgical technique in group II}

It was performed in programmed steps for all patients as follow:

All patients were operated under general anesthesia using nasal intubations of the normal side. Local anesthetic solution with vasoconstrictor agent (Mepivacaine HCL $2 \%$ with Levonordefrin $1 \backslash 20000)^{* * * *}$ was infiltrated in the surgical field to aid in homeostasis and facilitate soft tissue dissection.

The recipient site was approached first to prepare the graft bed before bone harvest to shorten the time needed for transportation of the graft and to preserve the vitality of the bone graft.

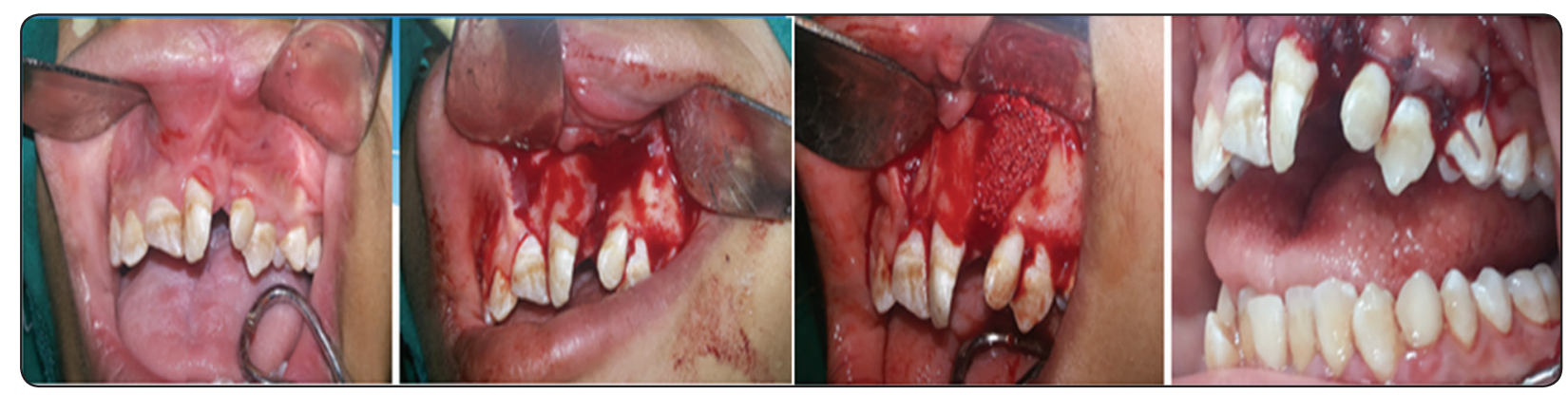

Fig (3) Surgical technique in group i: reflection of mucoperiosteal flap and repair of nasal layer, grating the cleft defect with Nano bone loaded with MSC , suturing of mucoperiosteal flap 


\section{The surgical technique for closure of the cleft site (Recipient site):}

The surgical approach was performed according toTessier et al; $\mathbf{2 0 0 5}^{[21]}$ as following : Creation of labial mucogingival flap on either side of the alveolar cleft, the incision continued for elevation of greater segment labial flap through the gingival sulci of both central incisors, the submucosal dissection superiorly to the oronasal fistula separating the muscle and connective tissue from the nasal mucosa, the nasal mucosa was reflected palatally from the walls of the cleft, and superiorly from the nasal septum on one side and the lateral nasal wall on the other side.

A palatal incision was then made around the teeth beginning posteriorly at each first molar until the fistula site was approached at the alveolar cleft; the nasal mucosa was separated at its point of attachment to the palatal mucosa. The separated nasal mucosa was swept back into the floor of the nose, the nasal mucosa wound edges were freshened and sutured to achieve closure with 4-0 Vicryl suture material. The elevated palatal flap was freshened along the previous fistula tract with removal of any granulation tissue and sutured using 3-0 Vicryl suture to achieve a watertight palatal closure.

\section{The surgical technique for bone graft harvest:}

A local anesthetic containing vasoconstrictor was infiltrated into the soft tissues overlying the anterior mandible prior to making the incision. A vestibular incision was made on the alveolar mucosa just below the attached gingiva between the second premolar regions. The mandibular symphysis was widely exposed until the lower border of the mandible. A $5 \mathrm{~mm}$ safety margin below the apices and 3-5 mm thickness of the lower border was respected. After harvesting a monoblock corticocancellous bone graft, cancellous bone were harvested from the bony cavity with large curettes, the lingual cortex was left intact.
The cleft site was filled with monoblock the bone graft then the remaining spaces was filled by cancellous bone. The soft tissue coverage of the graft (oral layer) was done using local mucoperiosteal flap:

\section{Postoperative follow up:}

The patients in both groups were followed up for 18 months postoperatively both clinically and radiographically:

Clinically to evaluate the wound healing, infection and postoperative edema and pain outcome, eruption of cleft related teeth through the graft and radiographically to determine graft incorporation and measure local bone mineral density at the follow up periods (1st, 3rd 6th and 18 month)

Maxillary expansion which was in need to correct posterior cross bite was performed by using Bonded Hyrax maxillary expander. This type of appliance used a special type of screw called HYRAX (Hygienic Rapid Expander). The screws have heavy gauge wire extension to be adapted to follow the contour of the palate. The jack screw was attached to a splint covering variable numbers of teeth. The activation was performed as two turns each day for 4-5 days and then one turn per day till the desired expansion was achieved ${ }^{[22]}$. The expansion appliance must be used as a retainer at least for 3 months after expansion to prevent the relapse.Maxillary expansion was examined by measuring $(\mathrm{C}-\mathrm{C})$ from a point that is $8 \mathrm{~mm}$ below the crest of interdental papilla distal to the canine on one side to the other(if canine fossa was no tobviously distinguishable ${ }^{[22]}$, intermolar width(M-M)(measured from central fossa of maxillary first molar to the central fossa of the other maxillary first molar) and inter tuberosity distance(T-T)(measured from the heist point of convexity of the tuberosity) pre and postoperatively for both groups. 


\section{Statistics}

The quantity and quality of bone formation after surgery during the follow up periods were compared between the two groups using a Mann-Whitney test. Data were expressed as mean \pm SD. A value of $p<0.05$ was considered statistically significant.

\section{RESULTS}

\section{Clinical results:}

\section{In Group I}

Early post-operative follow up showed that successful healing left no fistula or oronasal communication. No problems of wound healing, no swelling or discharge were seen during follow-up. The patients gained closure of the alveolar arch and stabilization of the teeth adjacent to the cleft.

The clinical follow up after 18 months postsurgery as palatal expansion was performed revealed that the rate of expansion as correction of cross bite took about 4-6 weeks with a significant increase in $\mathrm{C}-\mathrm{C}, \mathrm{M}-\mathrm{M}$ widths and T-T distance. The clinical examination of the grafted sites were appeared with normal ridge width that was good to accommodate the erupting permanent lateral incisor and canine (figure 4 tables 1,2).
TABLE (1) Intercanine width (C-C), intermolar width (M-M) and intertuberosity distance in group I (G I) and group II (G II)before and after maxillary expansion:

\begin{tabular}{|c|c|c|c|c|}
\hline & Before & After & t. test & p. value \\
\hline G I (C-C) & $24.50 \pm 2.14$ & $30.00 \pm 2.45$ & 22.892 & $0.001^{*}$ \\
\hline G II (C-C) & $24.50 \pm 2.33$ & $28.63 \pm 2.50$ & 11.638 & $0.004^{*}$ \\
\hline G I (M -M) & $34 \pm 1.6$ & $38.2 \pm 1.5$ & 6.524 & $0.032^{*}$ \\
\hline G II (M-M) & $34.5 \pm 1.9$ & $37.5 \pm 1.8$ & 5.984 & $0.043^{*}$ \\
\hline G I (T-T) & $35.50 \pm 1.60$ & $43.00 \pm 1.69$ & 82.895 & $0.001^{*}$ \\
\hline G II (T - T) & $36.50 \pm 2.27$ & $42.75 \pm 2.60$ & 26.189 & $0.001^{*}$ \\
\hline
\end{tabular}

TABLE (2) Comparison of C-C, M-M widths and T-T distance between both groups after maxillary expansion:

\begin{tabular}{|c|c|c|c|c|}
\hline & G I & G II & t. test & p. value \\
\hline $\begin{array}{c}\text { (C-C) } \\
\text { After }\end{array}$ & $30.00 \pm 2.45$ & $28.63 \pm 2.50$ & 1.113 & 0.287 \\
\hline $\begin{array}{c}\text { (M- M) } \\
\text { After }\end{array}$ & $38.2 \pm 1.5$ & $37.5 \pm 1.8$ & 0.743 & 0.421 \\
\hline $\begin{array}{c}\text { (T - T) } \\
\text { After }\end{array}$ & $43.00 \pm 1.69$ & $42.75 \pm 2.60$ & 0.234 & 0.823 \\
\hline
\end{tabular}

Fig (4) Postoperative photos for patient in group I during periods of palatal expansion 


\section{In group II:}

Early post-operative follow up showed that two patients at $3^{\text {rd }}$ week postoperative complain from graft dehiscence with loss of some graft particles. These cases were treated by daily irrigation with sterile normal saline and application of periodontal back and maintenance of good oral hygiene by using cholorihexidene mouth wash (MACRO pharmaceutical group. Egypt) 3 times daily until the wound was completely healed.

The clinical follow up after 18 months postsurgery as palatal expansion was preformed revealed that palatal expansion was performed with a significant increase in $\mathrm{C}-\mathrm{C}, \mathrm{M}-\mathrm{M}$ widths and T-Distance. Cross bite was corrected taking 4-6 weeks.

\section{Radiographic results:}

\section{In group I}

The radio-opacity of serial CTs slicing the middle level of the alveolar cleft in the grafted region increased gradually over the time as the mean of bone mineral density of bone bridge was 552 \pm 15.3immediatelly postoperative. This value was increased by time to $563 \pm 19.3$ and $583 \pm 28.04$ at 3 months and 6 months postoperatively respectively.

The radio-opacity of serial CTs slicing the middle level of the alveolar cleft in the grafted region after 18 months and complete the expansion of the palate was increased and as the mean of bone mineral density of bone bridge was $620+19.5$ which was nearly as the normal adjacent bone (Figure5. Table 3).

\section{In Group II}

The radio-opacity of serial CTs slicing the middle level of the alveolar cleft in the grafted region was decreased gradually over the time as the mean of bone mineral density of bone bridge was 548 \pm 27.3 immediately postoperative. This value was decreased by time to $254.25+41.27$ at 3 months then increased to $370 \pm 23.3$ at 6 months postoperatively respectively .

The radio-opacity of serial CTs slicing the middle level of the alveolar cleft in the grafted region after 18 months and complete the expansion of the palate was increased and the as the mean of bone mineral density of bone bridge was $563+16.19$ which lower than the normal adjacent bone (Figure 6. table 3)

TABLE (3) The radio-opacity of serial CTs slicing the middle level of the alveolar cleft in the grafted region over the follow up periods in both groups

\begin{tabular}{|c|c|c|c|}
\hline Time & Group I & Group II & P value \\
\hline $\begin{array}{c}\text { Immediate } \\
\text { postoperative }\end{array}$ & $552 \pm 15.3$ & $548 \pm 27.3$ & 0.213 \\
\hline 3 months post & $563 \pm 19.3$ & $254.25+41.2$ & 0.001 \\
\hline 6 months post & $583 \pm 28.04$ & $370 \pm 23.3$ & 0.002 \\
\hline 18 months post & $620+19.5$ & $563+16.19$ & 0.06 \\
\hline
\end{tabular}

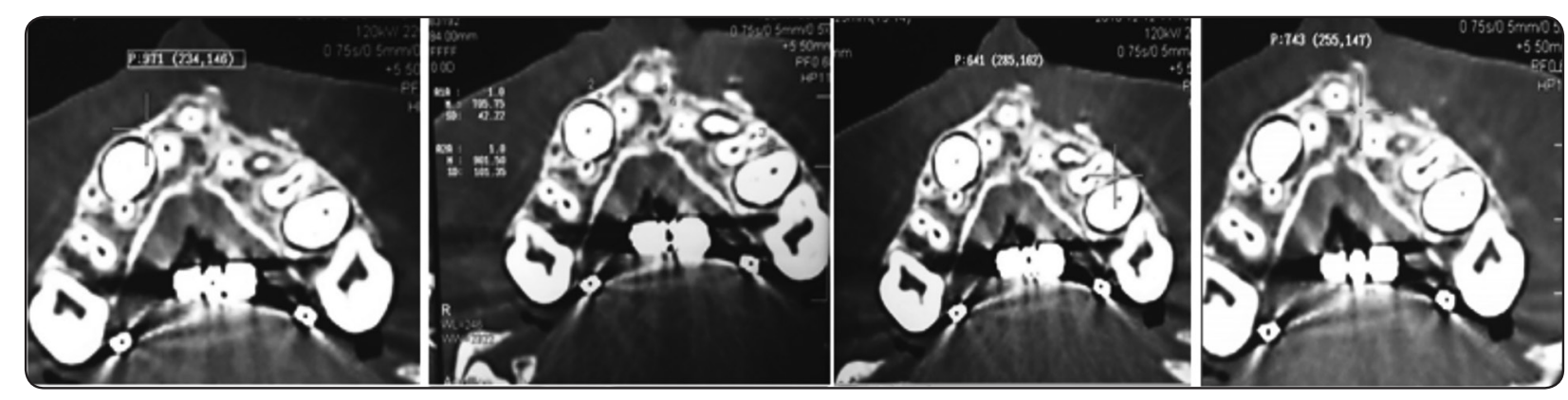

Fig (5) Postoperative photoradiographs for group I 


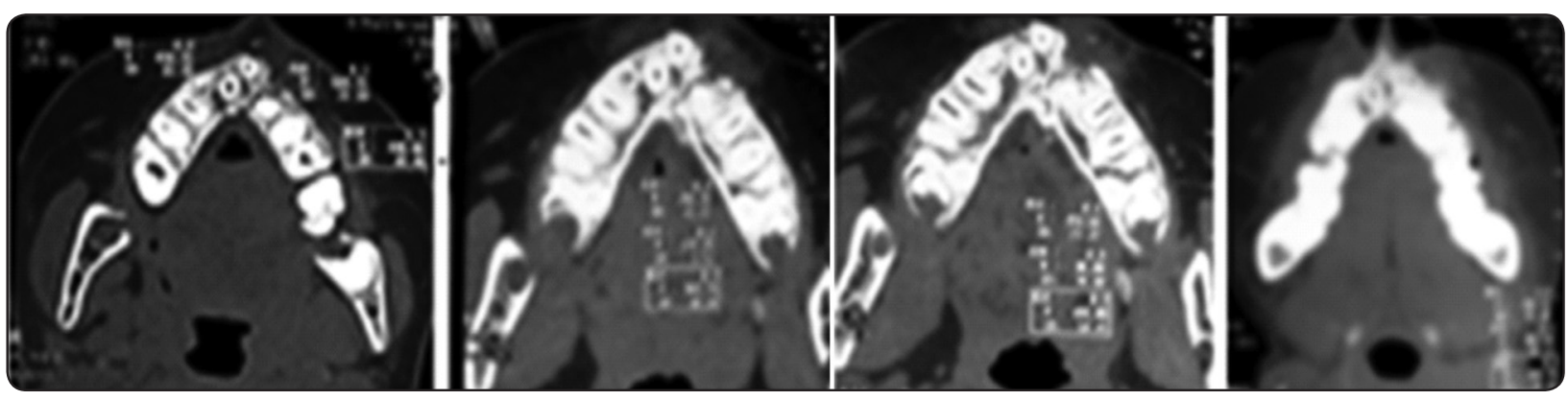

Fig (6) Postoperative photoradiographs for group II .

In comparing the radiographic results of both groups, it was revealed that the radio opacity of the bone bridge in group I is higher than that of group II with significant difference at 3 and 6 months postoperative as $\mathrm{P}$ values were 0.001 and 0.002 at 3 and 6 months postoperative respectively(Table 3 ).

\section{DISCUSSION}

CLP management by reconstruction of the alveolar process through an alveolar bone graft has many benefits. These benefits include restoring of continuity of the dental arch, correction of upper lip and nose deformations, and speech disturbance, eruption of permanent teeth, posterior dental prosthetic rehabilitation. Alveolar grafting also supports and gives stability to the wing of the nose, improving nasal emission and phonetics by closure of oronasal communication, orthodontic movement, and the insertion of dental implants. Also, better oral hygiene establishment, and limitation of growth disturbances can be achieved ${ }^{[23-25]}$.

Alveolar bone defects can be reconstructed by autogenous bone. Multiple donor sites have been suggested including the anterior and posterior iliac crest, proximal tibia, rib, and calvarial bone ${ }^{[26,27]}$. Regeneration of alveolar bone defect describedin1965 was done by gingivalperiosteoplasty(GPP). It was considered as an alternative technique without the potential complications of having a donor site at early age ${ }^{[28]}$. Although it had a variable rates of success of bone regeneration on the alveolar defects, it showed long term complications on facial growth ${ }^{[29]}$.
Although reconstruction of alveolar bone defects by autogenous bone graft has many objectives, it remains controversy. These controversies include optimal time to complete bone graft, origin of bone graft material, limited amount of bone needed, resorption of grafted bone, soft tissue necrosis especially of the palate and morbidity of donor site $^{[30]}$.

Tissue engineering studies have identified alternative methods that may allow early rehabilitation and decreased average number of operations until adult age.

MSC differentiation capacity into damaged tissues are still not well understood ${ }^{[31]}$.

Accordingly, the aim of this study was to evaluate the bone quality and quantity at the alveolar cleft sites that were repaired with autogenousmesynchyal stem cell and its effect on orthodontic dental arch expansion and compare these results with cases treated with autogenous chin bone graft.

Many authors prefer maxillary expansion after grafting of bone as the graft is set under a dynamic load during healing, soft tissue defect will be small to be closed and the bony defect will be narrow so it will be regenerated more rapidly ${ }^{[24,32]}$. While, presurgical orthodontic expansion is preferred by others to give easier expansion due to less resistance, closing the nasal floor can be done by enhancing access to the cleft, better postoperative cleaniness and hygiene, and less possibility of reopening the oronasal fistula ${ }^{[7,24]}$. 
As the main difference in the treatment convention in the management of cleft lip and palate is the time at which the graft is performed, alveolar bone graft can be classified as primary, secondary and tertiary. Bone graft is considered primary when it occurs early in life. This early intervention can cause impairment of the maxillary growth as it believed by some authors ${ }^{[33]}$. Bone graft is considered secondary, when it is placed in the mixed dentition before or after eruption of the permanent canines in order to provide adequate periodontal support for their eruption and preservation of the teeth adjacent to the cleft. By the age of eight $95 \%$ of the anteroposterior and transverse growth is completed. When bone graft is placed in the permanent dentition, it is considered as Tertiary. Tertiary bone graft cannot repair bone loss in teeth adjacent to the cleft but it assists in the closure of persistent oronasal fistulae and it helps prosthodontic and periodontal rehabilitation ${ }^{[30]}$.

Accordingly, secondary bone graft was performed in this work between the age 7-12 years as most of anteroposterior and transverse growth is completed by 8 yrs and only vertical growth remains. So, grafting does not have much effect on growth of midface and will give adequate bony support for the eruption of the canine ${ }^{[34]}$.

Dickinson et al; in $2008^{[12]}$ were in line with this work as they stated that when bone graft is performed in older patients with cleft lip and/or cleft palate, they may experience slow wound healing, bone graft absorption or recurrent fistulae, leading to failure of tooth eruption, while, early treatment may stay away from these unsuitable results.

Early post-operative follow up in group I (MSC group) showed that successful healing left no fistula or oronasal communication. No problems of wound healing, no swelling or discharge were seen during follow-up. The patients gained closure of the alveolar arch and stabilization of the teeth adjacent to the cleft.
This can be explained by that the MSCs can promote the healing of both bone at the grafted site and also the healing of soft tissue coverage. This result is in agreement with study of Horswel and Henderson ${ }^{[35]}$, as they stated that mesenchymal stem cells (MSCs) are able to form new bone when transplanted .MSCs can secrete various bioactive molecules that regulate cell growth, proliferation, fibrosis, angiogenesis and immune suppression to facilitate their use for allogenic transplantation.

The clinical examination of the grafted sites after 12 months post-surgery revealed that they appeared with normal ridge width that was good to accommodate the erupting permanent lateral incisor and canine

While clinical early post-operative follow up in group II (chin bone graft)showed that there were postoperative complain from graft dehiscence with loss of some graft particles in some patients. The clinical examination of the grafted sites after 12 months post-surgery showed that they appeared with narrow width and short height .

Rawashdeh and Telfah ${ }^{[36]}$ were in line with the present work as they stated that chin bone graft derived from the mandible has superior integration into the cleft defect as both the donor bone and recipient bed have the same intramembranous origin. They added that volume of corticocancellous blocks used to graft facial bony defects can be maintained when a membranous bone source is used rather than an endochondral bone.

However, symphysial bone graft is considered less suitable for large unilateral or bilateral cleft reconstruction because of its limited quantity available ${ }^{[36,37]}$. Radiographic CT scan showed that, the radio-opacity of serial CTs slicing the middle level of the alveolar cleft in the grafted region in group I was increased gradually over the time as the mean of bone mineral density of bone bridge was $552 \pm 15.3,563 \pm 19.3,583 \pm 28.04$ immediately 3 months and 6 months postoperatively respectively. This means that the new bone was continuously 
deposited at the graft site from the early stage of healing immediately postoperative and increased by time. After one year and complete the expansion of the density of palate bone was increased and as the mean of bone mineral density of bone bridge was $620+19.5$ which was nearly as the normal adjacent bone.

Results of the present study revealed no significant difference was found in rapid maxillary expansion (RME) between MSC group and group treated by autogenous chin bone graft. These results coincided with Huang et al; ${ }^{[38]}$.

On regarding to the radiographic results in group II (chin bone graft group: The radio-opacity of serial CTs slicing the middle level of the alveolar cleft in the grafted region was decreased gradually over the time as radio-opacity were $548 \pm 27.3$, and $254.25+41.2$, immediately and 3 months postoperative respectively. This value was increased to $370 \pm 23.3$ at 6 months postoperatively. The radio-opacity of serial CTs slicing in the same grafted region after one year and the expansion of the palate was increased to reach $563+16.19$ which is still lower than the adjacent normal bone.

In comparing the radiographic results of both groups, it was revealed that the radio opacity of the bone bridge in group I was higher than that of group II with significant difference at 3 and 6 months postoperative as $\mathrm{P}$ values were 0.001 and 0.002 at 3 and 6 months postoperative respectively. This supports the role of stem cell in early promotion of bone healing with good quantity as well as quality.

The results of this study were in agreement with studies of Dimitriou et al ${ }^{[39]}$ stated that combination of genetically engineered MSCs with synthetic bone substitutes, biomaterial scaffolds, decellularized allografts can stimulate the secretion of bone morphogenetic proteins (BMP) and regenerating the extracellular matrix by enhancing mechanical stability of the bone graft during formation and extending their long-term engraftment and differentiation in tissue. This combination can be used clinically for the treatment of non-healing wounds, scarring or functional replacement of tissue ${ }^{[30-42]}$.

Thus, Nano Bone ${ }^{\circledR}$ was used in the current study. It was the first Nano Bone technology product and was launched in 2005 .

Meier and Wolf ${ }^{[43]}$ go in line with this study as they found that no residual foreign substances can influence Nano Bone ${ }^{\circledR}$ natural biomechanics as the complete remodeling of Nano Bone ${ }^{\circledR}$ constitutes a decisive advantage. It can be totally substituted and remodeled by bone rather than xenogenic bone replacement material.

\section{CONCLUSION}

1. No significant difference was found in RME between MSC group and autogenous chin bone graft group.

2. MSCs grafting technique for alveolar cleft repair has a good role in early promotion of bone healing with good quantity as well as quality so, it can be used as an alternative method for treatment of alveolar cleft.

\section{CONFLICT}

This paper has no conflict of interest.

No fund.

\section{ACKNOWLEDGMENT}

We would like to thank members of orthodontic and surgical and maxillofacial departments for their help and support.

\section{REFERENCES}

1. Behnia H, Khojasteh A, Soleimani M, et al: Secondary repair of alveolar clefts using human mesenchymal stem cells. Oral Surg Oral Med Oral Pathol Oral RadiolEndod. 108:1-6,2009

2. Horswell BB, Henderson JM. Secondary osteoplasty of the alveolarcleft defect. J Oral MaxillofacSurg;61:1082-90, 2003. 
3. Long RE Jr, Spangler BE, Yow M. Cleft width and secondary alveolar bone graft success. Cleft Palate Craniofac J.;420:427-32.1995.

4. Mercado AM, Vig KWL. Orthodontic Principles in the ManagementOfOrofacial Clefts. In: Losee JE, Kirscher RE, eds. ComprehensiveCleft Care. New York: McGrawHill Medical;721-47,2009.

5. Freihofer HP, Borstlap WA, Kuijpers-Jagtmann AM, VoorsmitRA, , van Damme PA, Heidbüchel KL and Borstlap-Engels VM.Timing and transplant materials for closure of alveolar clefts. A clinical comparison of 296 cases. J Craniomaxillofac Surg.;21(4):143-8,1993.

6. LaRossa D, Buchmann S, Rothkopf DM, Mayro R, Randall P.A comparison of iliac and cranial bone in secondary grafting of alveolar clefts. PlastReconstr Surg.; 96:789-97, 1995.

7. Ochs MW. Alveolar cleft bone grafting (part II): secondary bone grafting. J Oral Maxillofac Surg.; 54:83-8,1996.

8. Walia, A. Secondary alveolar bone grating in cleft lip and palate patients Contemporary Clinical Dentistry ; 21: 14654, 2011.

9. Goudy, S., Lott, D., Burton, R., Wheeler, J. and Canady, J. Secondary alveolar bone grafting: Outcomes, revisions and new applications. The Cleft Palate-Craniofacial Journal.; 46, 610-612.2009.

10. Van Hout, W., van der Molen, A., Breugem, C.C. and Koole, R. Reconstruction of the alveolar cleft: Can growth factor-aided tissue engineering replace autogous bone grafting? A literature review and systematic review of results obtained with bone morphogenetic protein-2. Clinical Oral Investigations.;15, 297-303,2011.

11. Eppley, B. and Sadove, A. Management of alveolar cleft bone grafting - State of the art. The Cleft PalateCraniofacial Journal. 2000; 37, 229-33.

12. Dickinson BP, Ashley RK, Wasson KL, O'Hara C, GabbayJ,Heller JB, Bradley JP. Reduced morbidity and improved healingwith bone morphogenic protein-2 in older patients with alveolarcleft defects. PlastReconstr Surg.; 121(1):209-17, 2008.

13. Bruder SP, Kraus KH, Goldberg VM, Kadiyala S. The effect ofimplants loaded with autologous mesenchymal stem cells on thehealing of canine segmental bone defects. J Bone Joint Surg Am;80:985-96, 1998.

14. Kon E, Muraglia A, Corsi A, Bianco P, Marcacci M, Martin I, etal. Autologous bone marrow stromal cells loaded onto poroushydroxyapatite ceramic accelerate bone repair in critical-size defectsof sheep long bones. J Biomed Mater Res;49:328-37,2000.

15. Lieberman JR, Daluiski A, Einhorn TA. The role of growthfactors in the repair of bone.Biology and clinical applications.J Bone Joint Surg Am;84-A:1032-44,2002.

16. Wozney JM. Overview of bone morphogenetic proteins. Spine;27:2-8,2002.

17. Kasten P, Luginbuhl R, van Griensven M, Barkhausen $\mathrm{T}$, KrettekC,Bohner $\mathrm{M}$, et al. Comparison of human bone marrow stromal cellsseeded on calcium-deficient hydroxyapatite, X-tricalciumphosphateand demineralized bone matrix. Biomaterials; 24:2593-603,2003.

18. Rueger JM, Linhart W, Sommerfeldt D. Biologic reactions tocalcium phosphate ceramic implantations. Results of animal experiments. Orthopade; 27:89-95,1998.

19. Vacanti CA, Bonassar LJ. An overview of tissue engineeredbone. ClinOrthop; 12:375-81. 1999.

20. Soleymani SY, Khojasteh A, Soleimani M, Alikhasi M, Khoshzan A, Ahmadbeigi N. Sinus augmentation using human mesenchymal stem cells loaded into a tricalcium phosphate/hydroxyapatite scaffold. Oral Surg Oral Med Oral Pathol Oral RadiolEndod; 106:203-9,2008.

21. Tessier P, Kawamoto H, Matthews D, Posnick J, Raulo Y, Tulasne JF, Wolfe SA. Autogenous bone grafts and bone substitutes-tools and techniques: A 20000- case experience in maxillofacial and craniofacial surgery. PlastReconstr Surg.; 116(5 Suppl):6S-24S; 2005.

22. Bhalajhi SI. Orthodontic The Art and Science. Fifth Edition.Arya-New Delhi.25, 179-80, 545-62,2009.

23. Arangio P, Marianetti TM, Tedaldi M, Ramieri V, and Cascone P, "Early secondary alveoloplasty in cleft lip and palate,'Journal of Craniofacial Surgery.; 19(5): 1364-69, 2008.

24. Peter, E., Larsen, D., Reconstruction of the Alveolar Cleft. Principles of Oral and Maxillofacial Surgery.Peterson's second ed.m.miloro. Vol. 2.859-70,2004.

25. Witsenburg B.The reconstruction of anterior residual bone defectsin patients with cleft lip, alveolus and palate. J Maxillofac Surg.; 13(5): 197-208,1985.

26. Baqain Z H, Anabtawi M, Karaky A A, MalkawiZ, Morbidity from anterior iliac crest bone harvesting for secondaryalveolar bone grafting: an outcome assessment study. J. OralMaxillofac. Surg.; 67 (3), 570-575,2009.

27. Eichhorn, W., Blessmann, M., Pohlenz, P., Blake, F.A., Gehrke, G.,Schmelzle, R., Heiland, M. Primary osteoplasty usingcalvarian bone in patients with cleft lip, alveolus and palate. JCranioMaxillofac.Surg.; 37 (8), 429-433,2009. 
28. Robinson F, Wood B. Primary bone grafting in the treatment of cleft lip and palate with special reference to alveolar collapse. Br J Plast Surg.;22(4):336-42,1969.

29. Sato Y, Grayson BH, Garfinkle JS, Barillas I, Maki $\mathrm{K}$, Cutting CB.Success rate of gingivoperiosteoplasty with and without secondary bone grafts compared with secondary alveolar bone grafts alone. PlastReconstr Surg.; 121(4):1356-69,2008.

30. Brand S, Blechschmidt A, Müller A, Sader R, SchwenzerZimmerer K, Zeilhofer HF, Holsboer-Trachsler E. Psychosocial functioning and sleep patterns in children and adolescents with cleft lip and palate (CLP) compared with healthy controls. Cleft Palate Craniofac J. :46(2):124-35, 2009.

31. Chamberlain G, Fox J, Ashton B and Middleton J. Concise review: Mesenchymal stem cells: Their phenotype, differentiation capacity, immunological features, and potential for homing. Stem Cells; 25: 2739-49,2007.

32. Da Silva Filho O G, Boiani E, de Oliveira Cavassan A, SantamariaJr, M. Rapid maxillary expansion after secondary alveolar bone grafting in patients with alveolar cleft. Cleft Palate Craniofac J.; 46 (3), 331-338,2009.

33. Batra P, Sharma J, Duggal R and Parkash H. Secondary bone grafting in cleft lip and palate with eruption of tooth intothe graft: A Case Report. J Indian SocPedodPrev Dent.; 22(1):8-12,2004.

34. Semb G. Effects of alveolar bone grafting on maxillary growthin unilateral cleft lip and palate patients. Cleft Palate J1988:25:288-295.

35. Horswell BB, Henderson JM. Secondary osteoplasty of the alveolarcleft defect. J Oral Maxillofac Surg; 61:108290, 2003.
36. Rawashdeh, M.A., Telfah, H. Secondary alveolar bone grafting:the dilemma of donor site selection and morbidity. Br J OralMaxillofac Surg.;46 (8), 665-670,2008.

37. Enemark, H., Jensen, J., Bosch, C. Mandibular bone graftmaterial for reconstruction of alveolar cleft defects: longtermresults. Cleft Palate Craniofac. J. 38, 155-163, 2001.

38. Huang J, Tian B, Chu F, Qian Y. Rapid maxillary expansion in alveolar cleft repaired with a tissue-engineered bone in a canine model. jmbbm.;48:86-99,2015.

39. Dimitriou R, Jones E, McGonagle D and Giannoudis PV. Bone regeneration: Current concepts and future directions. BMC Med; 9: 66,2011.

40. Johnson BQ, Fox R, Chen X and Thibeault S. Tissue regeneration of the vocal fold using bone marrow mesenchymal stem cells and synthetic extracellular matrix injections in rats. Laryngoscope; 120: 537-545,2010.

41. Meijer GJ, de Bruijn JD, Koole R and van Blitterswijk CA. Cell based bone tissue engineering in jaw defects. Biomaterials; 29:3053-3061,2008.

42. Macchiarini P, Jungebluth P, Go T, Asnaghi MA, Rees LE, Cogan TA, Dodson A, Martorell J, Bellini S, Parnigotto PP, Dickinson SC,Hollander AP, Mantero S, Conconi MT and Birchall MA. Clinical transplantation of a tissueengineered airway. Lancet; 372: 2023-2030,2008.

43. Meier J, Wolf E: Poster: Histomorphological and immunohistological findings after sinus lift procedures, Osteology Symposium (Monaco - May 10 $0^{\text {th }}-12^{\text {th } 2007) . ~}$ 